\title{
O tráfico de mulheres, crianças e adolescentes para fins de exploração sexual comercial
}

\author{
MARIA LÚCIA PINTO LEAL
}

Este estudo, trata do tráfico de mulheres, crianças e adolescentes para fins de exploração sexual comercial no Brasil sem a pretensão de esgotar todas as questões relativas à temática, porém buscando desenhar um cenário político e sociojurídico do fenômeno, tendo como referência a militância junto a sociedade civil $^{1}$, documentos institucionais, medidas normativas, pesquisas, dados de mídia e consultas a bancos de dados.

A inclusão desta temática na agenda pública brasileira foi determinada por denúncias realizadas por organizações estratégicas da sociedade civil, especializadas na defesa de temas relativos à mulher, às crianças e aos adolescentes, pela Organização das Nações Unidas (ONU) e pela Organização dos Estados Americanos (OEA), em nível local e global, em defesa dos direitos humanos, especialmente contra a violência, o abuso e a exploração sexual comercial, o crime organizado, o tráfico de seres humanos e a escravidão.

A mobilização² da sociedade civil e suas expressões (ONGs, Fóruns e Movimentos Sociais) contra a exploração sexual comercial (tráfico para fins sexuais, pornografia, turismo sexual e prostituição) de crianças e adolescentes nos anos de 1990, articulada com as redes em nível local e global de combate ao tráfico de pessoas e ao crime organizado, agenda o debate público nacional e internacional do tráfico de crianças, adolescentes e mulheres para fins sexuais, em eventos de defesa dos direitos humanos,

Doutora em Serviço Social, professora do Departamento de Serviço Social da UnB.,

1 Para Gramsci, sociedade civil é representada como o terreno dos conflitos econômicos, ideológicos, sociais e religiosos que o Estado tem a seu cargo resolver, intervindo como mediador ou suprimindoos; com base nela, partem as solicitações às quais o sistema político está sendo chamado a responder, como o campo das várias formas de mobilização, de associação e de organização das forças sociais que impelem à conquista do poder político. (Cf. Bobbio, 1982). Por exemplo, as ONGs são consideradas neste estudo como uma das expressões da sociedade civil organizada, ou espaços políticos de correlação de forças e conflito de poderes, entre sociedade e Estado e devem ser vistas com respeito ao seu caráter contraditório.

2 A concepção de mobilização social adotada para este estudo privilegia o aspecto político do conceito e entende que mobilização social é uma ação dirigida politicamente pela sociedade civil e suas expressões (ONGs, Fóruns, Movimentos Sociais e Conselhos) ou o lugar do enfrentamento da violência sexual contra mulheres, crianças e adolescentes, estratégia para incluir e ampliar 
tais como: IV Conferência de Mulheres em Beijing, em 1995; a Consulta das Américas contra a Exploração Sexual Comercial de Crianças e Adolescentes, realizada em Brasília, em 1996; a Convenção da ONU contra o Crime Organizado Transnacional, em Palermo, em 2000, e no II Congresso Mundial contra a Exploração Sexual Comercial de Crianças, realizado em Yokohama, em 2001.

Esta articulação política entre as organizações aproxima estrategicamente a temática da exploração sexual comercial de crianças, adolescentes e mulheres com o tráfico de seres humanos, problematizando a questão do tráfico de mulheres, crianças e adolescentes para fins de exploração sexual comercial no contexto mundial.

A declaração aprovada durante o Primeiro Congresso Mundial contra a Exploração Sexual Comercial de Crianças, que se realizou em Estocolmo, em 1996, definiu a exploração sexual comercial da infância como:

"a exploração sexual comercial de crianças é uma violação fundamental dos direitos da criança. Esta compreende o abuso sexuaß ${ }^{3}$ por adultos e a remuneração em espécie ao menino ou menina e a uma terceira pessoa ou várias. A criança é tratada como um objeto sexual e uma mercadoria. A exploração sexual comercial de crianças constitui uma forma de coerção e violência contra crianças, que pode implicar o trabalho forçado e formas contemporâneas de escravidão."

O Instituto Interamericano del Nino classificou, em 1998, a exploração sexual comercial em quatro modalidades: tráfico para fins sexuais, prostituição, turismo sexual e pornografia, e essa classificação foi incorporada nas agendas internacionais relativas à exploração sexual comercial de crianças e adolescentes (Leal, M.L.P. 1998, p. 23). Em todo o mundo, inclusive nas Américas, pesquisas ${ }^{4}$ têm demonstrado que são as mulheres, crianças e os adolescentes, os mais envolvidos, embora informações atuais indiquem a presença também de crianças do sexo masculino.

as demandas de classe, gênero, raça e etnia no âmbito das políticas sociais (Leal, M.L.P., 2001, p.1). Portanto, o objetivo maior de uma ação mobilizadora é a de fortalecer os direitos sociais dos segmentos em situação de violação contando com uma intervenção política referendada por um poder coletivo emanado da sociedade.

3 Conceito de abuso sexual - abuso sexual de crianças e adolescentes - ato ou jogo sexual em que $o$ adulto submete a criança ou o adolescente (relação de poder desigual) para se estimular ou satisfazer sexualmente, impondo-se pela força física, pela ameaça ou pela sedução, com palavras ou com a oferta de presentes (ANDI, 2002 p.44). Não tem implicações comerciais, na medida que não intervém nas forças de mercado nem se produz nenhum benefício secundário, do ponto de vista material (UNICEF, 2002, p.7).

4 Pesquisa sobre Tráfico de Mulheres, Crianças e Adolescentes para Fins de Exploração Sexual Comercial, 2002; Investigación Regional sobre Tráfico, Prostituición, Pornografia Infantil y Turismo 
O Instituto Internacional de Leis e Direitos Humanos da De Paul College/OEA (2000, p. 1) decidiu concentrar a discussão sobre a exploração sexual comercial de mulheres, crianças e adolescentes (ambos os sexos), porque as vítimas deste grupo se encontram entre as mais vulneráveis e com uma maior necessidade de assistência. De um modo geral são consideradas delinqüentes em vez de sujeitos violados e por tanto recebem uma menor proteção legal quando as autoridades investigam a natureza comercial do problema.

De acordo com Nogueira Neto (2001, p. 1), esse corte de gênero (mulheres) e de geração (crianças/adolescentes) se faz relevante, por serem essas, indiscutivelmente, as formas mais emblemáticas e mais incidentes de exploração e violência sexual. Entretanto, é preciso registrar que sofrem igualmente essas discriminações, explorações e violências, outros segmentos sociais vulnerabilizados ou em desvantagem social, onde se incluem também os transgêneros e determinados homens (homossexuais, travestis e outros).

Na legislação internacional ${ }^{5}$ o tráfico de pessoas é o recrutamento, o transporte, a transferência, o alojamento ou a recolha de pessoas, pela ameaça de recursos, à força ou outras formas de coação, por rapto, por fraude e engano, abuso de autoridade ou de uma situação de vulnerabilidade, ou através da oferta ou aceitação de pagamentos, ou de vantagens para obter o consentimento de uma pessoa que tenha autoridade sobre uma outra para fins de exploração (termos do protocolo de Palermo, art. 2obis, alínea a).

Este conceito apresenta algumas restrições pois somente trata de definir e tipificar o tráfico internacional, em detrimento do tráfico interno, configurado no Brasil por denúncias, estudos e pesquisas (CECRIA, 2002). Além disso, apresenta-se muito genérico e preso ao texto da violência criminal, deslocado de uma análise macrossocial e cultural.

Entretanto, o aspecto genérico da lei torna-se estratégico uma vez que amplia o objeto, isto é, inclui todas as formas de tráfico humano (para a exploração sexual comercial e outras formas de trabalho forçado

\footnotetext{
A comunidade internacional condenou repetidamente a escravidão involuntária, violência contra as mulheres e outros elementos de tráfico, através de declarações, tratados, resoluções e relatórios das Nações Unidas, incluindo a Declaração Universal dos Direitos Humanos; a Convenção Suplementar sobre a Abolição da Escravatura, Comércio de Escravos, Instituições e Práticas Similares à Escravidão, de 1956; a Declaração Norte Americana dos Direitos e Deveres do Homem, 1948; a Convenção sobre o Trabalho Forçado, de 1947; a Convenção Internacional sobre os Direitos Civis e Políticos; a Convenção contra a Tortura e Outros Tratamentos ou Punições Cruéis, Desumanas ou Degradantes; as Resoluções números 50/167, 51/66 e 52/98 da Assembléia Geral das Nações Unidas; o !o Relatório do Congresso Mundial contra a Exploração Sexual Comercial de Crianças, 1996; a IV Conferência Mundial sobre as Mulheres (Pequim, 1995) e o Documento de Moscou da Organização para a Segurança e Cooperação na Europa, de 1991.
} 
e escravo) e descarta idade e sexo. De acordo com Ann Jordan (2002, p. 02), o Protocolo de Prevenção, Supressão e Punição do Tráfico de Pessoas, assinado em Palermo, em 2000, não incorpora totalmente os padrões internacionais de direitos humanos, quando não exige que os governos garantam proteção e assistência às vítimas de tráfico. Alerta que a legislação doméstica necessita, portanto, solucionar essa falha séria da comunidade internacional.

Outro comentário sobre a lei diz respeito ao termo "consentimento", atualmente objeto de polêmica:

"Essa questão abrange o debate sobre se uma mulher pode consentir na prostituição. Alguns dizem que não, mas os defensores dos direitos humanos afirmam que os trabalhadores do sexo têm direitos como quaisquer outros trabalhadores. Alguns baseiam seus argumentos na irrefutável presunção de nulidade de qualquer concordância com a prática da prostituição e outras formas de trabalho sexual que se fundamentem na natureza lucrativa dessa atividade. Outros apoiam esse ponto de vista porque consideram esse tipo de consentimento para se prostituir, como resultado da coação econômica ou abuso de vulnerabilidade econômica da pessoa em questão. Aqueles que se posicionam no lado contrário do debate sustentam que as mulheres podem admitir livremente em se tornarem trabalhadores sexuais e que essa escolha deve ser respeitada. Existe consenso quanto à incapacidade de um menor de idade dar consentimento válido a esse tipo de exploração mas, ainda assim, discute-se qual a idade para o consentimento à luz da diversidade cultural no mundo. Esses debates têm enfraquecido os esforços dos que desejam impedir essa prática desumana." (Bassiouni, 2002, p. 03).

O Código Penal brasileiro não trata do tráfico de pessoas em geral, apenas de mulheres para prostituição e em nível internacional, conforme texto da lei a seguir: $O$ "tráfico internacional de mulheres para fins de prostituição", como tipificado em seu artigo 231.

Quanto à legislação referente à criança e ao adolescente, a "submissão de crianças e adolescentes à prostituição e à exploração sexual comercial" e o "lenocínio", são tipificados, respectivamente, no artigo 244-A do Estatuto da Criança e do Adolescente (ECA) e nos artigos 227, 228 e 229 do Código Penal. O Estatuto define o tráfico como: promover ou facilitar a saída ou entrada no território nacional de crianças e adolescentes sem a observância da lei de forma genérica (artigos 83, 84, 85 e 251). De acordo com ECA, torna-se difícil configurar o tráfico de crianças e adolescentes para fins de exploração sexual comercial. Desta forma, a estratégia é ter como referência o seu Art. 244-A para tipificar o crime.

No Brasil, o Ministério das Relações Exteriores examina o tráfico de crianças e adolescentes, no âmbito dos acordos internacionais relativos ao tema e informa que o País é signatário da Convenção sobre a Venda 
de Crianças à Prostituição Infantil e a Pornografia, na qual é considerada como venda de crianças

"todo ato de transação em virtude do qual uma criança é transferida para uma pessoa ou para um grupo de pessoas, a outra pessoa, em troca de remuneração ou de qualquer outra remuneração." (Brasil, 2001, p.5).

Além destes instrumentos internacionais, o Brasil também assinou e ratificou a Convenção relativa à Proteção das Crianças e à Cooperação em Matéria de Adoção Internacional e a Convenção sobre os Aspectos Civis do Seqüestro Internacional de Crianças, dois dos mais avançados textos jurídicos, relativos à repressão ao tráfico de crianças.

Na Décima Cúpula Ibero-Americano, realizada no Panamá, em 2000, os países participantes acordaram em incluir uma cláusula relativa ao tráfico de crianças na declaração final. No item 10 letra "C" da Declaração, os chefes de Estado e de governo dos 21 países ibero-americanos acordaram em impulsionar ações legislativas e adotar medidas severas que punam aqueles que participam ou colaboram no cometimento de delitos de tráfico, seqüestro, vendas de órgãos, exploração sexual comercial de crianças e adolescentes e/ou qualquer outra atividade ilícita que cause danos à sua dignidade e vulnerabilize os seus direitos.

Em discurso proferido no Colóquio Internacional sobre Tráfico de Mulheres e Crianças, promovido pela Associação Brasileira de Direito Penal, Bassiouni (2001, p. 2), comenta que apesar de a Organização das Nações Unidas ter aprovado a Convenção Internacional contra o Crime Organizado, em dezembro de 2000, em Palermo, a qual inclui um Protocolo de Prevenção, Supressão e Punição do Tráfico de Pessoas, especialmente o tráfico de mulheres e crianças, apenas seis nações ratificaram esta convenção e quatro outras ratificaram o Protocolo, quando seriam necessárias 40 ratificações.

Ainda de acordo com o referido autor, outras convenções relacionadas à escravidão e práticas equiparadas, tráfico de pessoas e exploração internacional da prostituição, mostraram-se inadequados. Um sinal revelador desta afirmação é que somente $25 \%$ dos países do mundo ratificaram a Convenção de 1949 para a Supressão do Tráfico de Pessoas e da Exploração da Prostituição e de Outros.

Como observamos no comentário acima, trata-se de um fenômeno de natureza complexa e singular, uma vez que envolve tráfico no contexto de gênero, geração, exploração sexual comercial e é crime. É no âmbito dos fóruns de discussão sobre a exploração sexual comercial de crianças e adolescentes, das Nações Unidas, da União Européia e do Parlamento 
Europeu que vamos encontrar fundamentos teóricos, metodológicos e especializados para construir um conhecimento sobre esta temática.

As Agendas e Planos de Ação, elaborados nesses fóruns, apontam questões estratégicas para o enfrentamento do fenômeno, em nível nacional e internacional, tais como:

- o fenômeno é multidimensional, multifacetado e complexo e os fatores determinantes são de ordem política, socioeconômica, cultural, jurídica e psicológica;

- o tráfico de mulheres, crianças e adolescentes é transnacional e ocorre, também, dentro de seus próprios países e nas fronteiras, e são explorados não somente nas atividades sexuais comerciais (prostituição, turismo sexual, pornografia e tráfico para fins sexuais) como em outras formas de trabalho forçado e escravo (na agricultura, na fabricação de produtos, nas casas de entretenimento, na pesca e nos serviços domésticos);

- existe dificuldade em dar visibilidade ao fenômeno por se tratar de uma questão relativa ao crime organizado e por envolver corrupção, e, além disso, há fragilidade das redes de notificações nas estruturas de poder, especialmente as governamentais, para fornecer uma radiografia do fenômeno e contar com o testemunho de vítimas ou informantes;

- cada país adota uma legislação específica para o assunto e quando se trata de tráfico internacional, esse quadro legal torna-se uma barreira para o seu enfrentamento, assim como a ausência de uma legislação para regular o tráfico interno;

- ampliar o debate que existe em torno da questão do consentimento da vítima em ser ou não objeto do tráfico para fins de exploração sexual comercial;

- estabelecer as especificidades entre o tráfico para fins sexuais, envolvendo crianças, adolescentes e mulheres:

- e, finalmente, examinar o impacto da globalização no acirramento e expansão do tráfico para fins sexuais e a fragilidade dos Estados-Nações no enfrentamento da questão.

A tendência é estabelecer uma relação objetiva entre a globalização e o tráfico de seres humanos. Quando analisado nesta ótica, o fenômeno emerge como uma economia clandestina e ilegal, organizada em redes locais e transnacionais, estruturadas através de mecanismos que viabilizam o recrutamento e o aliciamento de mulheres, crianças e adolescentes reforçando o estado de dependência social, econômica e psicossocial destes segmentos. 
O tráfico no contexto da globalização de mercado articula com redes de colaboração global, interconecta mercados e atividades criminosas que, facilitadas pela tecnologia, pelos avanços dos sistemas de transportes, pela internacionalização da economia e pela desregulamentação dos mercados, movimentam enormes somas de dinheiro. Isto é, os mercados locais e globais do crime organizado das drogas e do tráfico para fins sexuais, por exemplo a Yakusa, as Tríades Chinesas, a Máfia Russa e os Snakes Head são responsáveis pela transação de quase um bilhão de dólares no mercado internacional de tráfico humano (ONU, 2001).

Essas redes do crime organizado têm submetido Estados e enfraquecido governos, especialmente, quando elas encontram espaços nas teias das políticas de desenvolvimento e crescimento econômico, em nível local e mundial (FMI, BID e outros) para tecerem as redes de tráfico de mulheres, crianças e adolescentes para fins de exploração sexual comercial. Estes projetos facilitam a expansão do crime organizado e acirram as desigualdades sociais, de gênero, raça e etnia, bem como provocam impactos danosos no meio ambiente e nas relações culturais locais. Um exemplo concreto dessa relação de exploração e dominação, é a política de turismo globalizada que vem provocando a expansão da indústria do turismo sexual, cujos atores mais envolvidos são as mulheres, crianças e adolescentes. ${ }^{6}$

A questão que sobressai diz respeito a determinados indicadores macrossociais que explicam as razões da existência do tráfico de mulheres, crianças e adolescentes para fins de exploração sexual comercial, tal como o impacto da política de desenvolvimento e crescimento econômico, na expansão da indústria do sexo, na migração, na precarização do trabalho adulto, da criança, do adolescente e no crime organizado para a exploração sexual comercial.

Em termos de Brasil, a inter-relação do tráfico de mulheres, crianças e adolescentes para fins de exploração sexual comercial se configura da seguinte forma: no Nordeste, o indicador relevante é o turismo sexual; no Norte, a prostituição; no Centro-Oeste, a prostituição e o turismo de pesca; no Sudeste, o turismo sexual, a prostituição e a pornografia; e no Sul a prostituição e o tráfico para adoção ilegal (cf. Banco de Dados da RECRIA/CECRIA).

Entretanto, as formas de recrutamento de mulheres, crianças e adolescentes não ocorrem apenas no contexto da exploração sexual

${ }_{6}$ Cf. estudos do Centro Humanitário de Ajuda à Mulher (CHAME), de Salvador (BA), de 2000, e do Programa Mujer, Justicia e Género (2000).

${ }^{7}$ Vide pesquisa sobre exploração sexual comercial de crianças e adolescentes e trabalho doméstico (OIT, 2002). 
comercial, elas ocorrem também através do trabalho doméstico ${ }^{7}$; na agricultura, na indústria, no setor terciário, nas redes de entretenimento, dentre outras.

De acordo com o Relatório sobre o Tráfico Internacional de Mulheres e Crianças Associação Internacional de Direito Penal,

"Nos últimos cem anos, o Brasil passou da condição de país de destino para país fornecedor do tráfico internacional de mulheres e crianças. Apesar de ser um tema flagrante não há estatísticas confiáveis, no Brasil, para fornecer um precisa idéia da sua extensão. É certo que o país está às voltas com o tráfico de mulheres, sobretudo para fins de exploração sexuais. Mas o tráfico de crianças para a adoção ilegal e a migração ilegal também são questões presentes no país." (AIDP, 2002, p. 1).

A Associação Internacional de Direito Penal afirma que a Fundação Helsinque para os Direitos Humanos informou que 75 mil mulheres brasileiras estão atualmente envolvidas no mercado sexual da União Européia. Afirma ainda que desde, os anos de 1990, o tráfico vem sendo admitido dentro dos limites territoriais do país. E que tráfico de seres humanos no Brasil configura-se como sendo para a exploração sexual comercial de mulheres, e meninas para adoção internacional ilegal, turismo sexual e trabalho forçado.

A invisibilidade da questão é um fato no Brasil. A pesquisa sobre A Infância na Mídia, realizada pela Agência de Notícias dos Direitos da Infância (2002, p. 37) mostra que a radiografia da exploração sexual comercial de crianças e adolescentes (prostituição, tráfico, turismo sexual e pornografia) não é muito visível nas estruturas de poder das organizações governamentais.

Este fato também está sendo confirmado pela pesquisa, ainda em andamento, sobre tráfico de mulheres, crianças e adolescentes no Brasil, coordenada pelo Centro de Referência, Estudos e Ações sobre Crianças e Adolescentes (CECRIA, 2002). Essa organização aponta a existência do tráfico internacional de mulheres jovens, através de inquéritos levantados junto aos órgãos jurídicos, junto à mídia e às ONGs e já apresenta estudos de casos detalhados sobre o fenômeno. Identifica também, o tráfico de crianças e adolescentes para fins sexuais, em nível interno, mesmo sem ter uma lei que tipifique os casos de tráfico doméstico.

A Polícia Federal apresentou uma estatística de 38 inquéritos policiais no ano de 2000 para apuração de crimes tipificados nos Artigos 227, 228, 229 e 231 do Código Penal brasileiro. No ano de 2001 foram instaurados 9 inquéritos policiais, dados obtidos até setembro de 2001. Através desses inquéritos policiais foi possível identificar as rotas mais utilizadas para o tráfico de mulheres para fora do país, tais como: Goiânia/ 
Rio de Janeiro/Europa; Recife/Fortaleza/Rio de Janeiro/Europa; Belém/ Suriname/Holanda; Rio de Janeiro/Israel; Rio de Janeiro/Europa; Paraná/ Rio de Janeiro/Europa:

"A maioria destas rotas tem como objetivo encaminhar as mulheres aliciadas para a Europa. Entretanto, pode-se observar que o país de chegada nem sempre é o país de destino. Como por exemplo, citamos os casos em que mulheres são enviadas para a França e, na realidade, cruzam as fronteiras via terrestre para a Espanha, onde serão exploradas. Os principais países da Europa de destino das mulheres aliciadas são Espanha, Holanda, Alemanha e Itália. Os principais focos de aliciamento de mulheres são Goiânia, Recife, Fortaleza, Belém, Rio de Janeiro e Espírito Santo." (Polícia Federal, 2002, p.2).

O Programa Mujer, Justicia e Género (2000) constata que a América Latina e o Caribe são as regiões com maior número de mulheres e meninas aliciadas para a indústria do sexo, tais como: Brasil, República Dominicana, Chile, Peru, Venezuela, Paraguai, Costa Rica, Honduras, Belize, dentre outros.

Nesta direção, os dados fornecidos por esse programa demonstram que, além do Brasil e da República Dominicana, a América Central conta com 2000 mil meninas que foram exploradas sexualmente pelas redes de tráfico em 1996. Destas, 1200 eram salvadorenhas, 500 nicaraguenses, e 300 gualtematecas. Afirma, também, que existe uma grande movimentação de mulheres e meninas entre a Colômbia, Venezuela e Equador, e uma porcentagem menor no Peru.

Nesta perspectiva, o tráfico de mulheres, crianças e adolescentes para fins de exploração sexual comercial ocorre de regiões periféricas ou semi-periféricas (Ảsia, África, América do Sul e Leste Europeu) e são encaminhados preferencialmente para países desenvolvidos (Estados Unidos, Europa Ocidental, Israel e Japão).

"Estima-se que anualmente entre 100.000 e 200.000 mulheres e crianças, algumas destas com apenas 6 anos de idade, são levadas para fora de seus países e sexualmente exploradas. A maior parte delas não chega aos 30 anos. Morrem de AIDS, outras doenças sexualmente transmissíveis, debilidade geral da saúde, ingestão de drogas e abusos físicos e psicológicos. (Bassiouni, 2002, p. 1).

Este quadro de tráfico internacional é observado no estudo de caso de Simone Borges Felipe, falecida em Bilbao, na Espanha, em 1996, de acordo com o dossiê da Polícia Federal:

“... Simone Borges Filipe, recém falecida em Bilbao/Espanha; que na primeira quinzena de janeiro de 1996, comunicou aos pais que iria trabalhar na Espanha a convite de Eleuza que morava nesta 
Capital na Vila Regina e hoje encontra-se na Espanha, que Simone disse que trabalharia de balcão ou restaurante acreditando que teria melhores condições, que Elicia, irmã de Eleuza, que também reside na Vila Regina, acompanhou Simone nesta Regional para requerer Passaporte, que Elicia apanhou Simone na sua residência para viajar em companhia desta para a Espanha, ocasião em que o depoente indagou de Elicia se era coisa séria, tendo a mesma afirmado que era coisa boa e que se não fosse Simone voltaria, que o depoente disse a Elícia que se algo acontecesse a sua filha, o depoente iria ao fim do mundo para saber, que quinze dias antes da viagem de Simone, Eleuza havia ido para Espanha fazendo-se acompanhar de outra moça de nome Cristina e em companhia de Elicia além de Simone mais duas moças viajaram para a Espanha, mais precisamente para Bilbao, que em 26 de janeiro do corrente ano, Simone viajou para a Espanha, que Simone costumava ligar de três em três dias, tendo ligado pela última vez oito dias antes de sua morte, que Simone havia dito ao depoente e a sua esposa que se por acaso as meninas Elícia e Eleuza fossem pedir mais dinheiro não era para dar, pois as duas alegavam que a Polícia Federal havia pego ambas e precisa de mil dólares de cada uma, que o depoente não tinha o endereço correto de Simone em Bilbao/Espanha e só depois da morte de Simone veio a tomar conhecimento de que sua filha estava trabalhando em um Cassino, chamado Clube César Palace de propriedade de Luís de la Sierra, que Simone ligou para sua mãe quinze dias após se encontrar na Espanha dizendo que estava ligando da rua e estava exausta e pediu para que fossem à Polícia Federal ou à Embaixada para retirá-las da Espanha que era um inferno, que Simone chorava o tempo todo e perguntou qual a hora no Brasil, tendo a mãe informado que eram oito horas da manhã e Simone dito que na Espanha já era meio-dia e que tinha trabalhado até aquela hora e estava exausta..."

O documento que versa sobre a Lei de Proteção às Vítimas do Tráfico e Violência (2002, p. 1), aprovado pelo Congresso dos Estados Unidos, reafirma a situação acima mencionada, quando relata que os traficantes objetivam, principalmente, mulheres e meninas, que são afetadas desproporcionalmente pela pobreza, falta de acesso à educação, desemprego crônico, discriminação e falta de oportunidades em países de origem.

Os traficantes atraem mulheres e meninas para as suas redes através de falsas promessas de condições decentes de trabalho, sob pagamento relativamente bom, como babás, domésticas, dançarinas, trabalhadoras em restaurantes, vendedoras ou modelos. Os traficantes também compram crianças de famílias pobres e as vendem para a prostituição ou diversos tipos de trabalho forçado ou cativo. 
As vítimas são muitas vezes forçadas, através de violência física, a dedicar-se a atos sexuais ou realizar trabalho similar à escravidão. Essa força inclui o estupro e outras formas de abusos sexuais, tortura, fome, prisão, ameaças, abusos psicológicos e coerção.

O tráfico expõe as vítimas a sérios riscos de saúde. As mulheres e crianças traficadas na indústria do sexo são expostas a doenças mortais, que incluem HIV e DST. As vítimas do tráfico às vezes são trabalhadas ou fisicamente brutalizadas até a morte.

Para o Unicef (2001, p. 5), é na combinação de mobilidade e de exploração que caracteriza o tráfico, sem importar quando ocorre realmente a exploração. Poderia ocorrer por exemplo ao começo mesmo do processo, quando uma mulher, um menino ou uma menina,a família ou a comunidade crê nas promessas de uma vida melhor em outra parte, maiores oportunidades de trabalho ou de recompensa, a promessa de assegurar contra descriminação e conflitos. Ainda, pode ocorrer se estas pessoas ou a família recebe documentos falsos que colocam a mulher e a(o) menor de idade em situação de submissão por causa de uma dívida, assim como em uma situação juridicamente vulnerável. Poderia ocorrer durante o processo, se alguém transporta ilegalmente a criança ou às vezes a toda a família através das fronteiras com uma situação de imigrante irregular. Pode ocorrer depois que a mulher, o menino(a) tenha sido transportado(a), "voluntariamente", sem saber o que pode passar ao final do processo.

Estas diferentes situações apresentadas vão traduzir, tanto o aspecto material da configuração do tráfico pela lei, através das condições objetivas (recrutamento, transporte, alojamento... de pessoas), como o aspecto subjetivo (sedução, coação, submissão, escravidão...) da situação o que vai revelar que para o tráfico ocorrer é necessário uma rede de profissionais e condições objetivas para organizar o mercado e o comércio.

As condições que movem o mercado do tráfico de pessoas, no contexto do crime organizado, é a oferta de mulheres, crianças e adolescentes em situação de vulnerabilidade social ${ }^{8}$, a demanda crescente para a compra de serviços sexuais (cujo acesso é facilitado pelos meios tecnológicos, utilizados na propaganda e marketing para atrair o consumidor) e a precária fiscalização por parte do governo ou afins, frente ao exercício deste mercado.

Este fenômeno tem inter-relação com os indicadores de mobilidade (movimento e/ou deslocamento de mulheres, crianças e adolescentes),

\footnotetext{
${ }^{8}$ Provocada por um conjunto de fatores coadjuvantes (exclusão social, ruptura familiar, violência intrafamiliar, arrimo de família ou sentimento de responsabilidade sobre ela, pressão familiar, discriminação ou marginalização por ser mulher, precarização do trabalho, baixa politização e conhecimentos de seus direitos, baixa escolaridade...).
} 
de migração e de fronteiras, os quais são diretamente afetados pelos impactos das questões macrossociais e culturais.

A mobilidade ou o deslocamento de mulheres, crianças e adolescentes, para dentro e fora do Brasil, atraídos por melhores condições de vida, de consumo e de novas experiências, se dá via correntes migratórias que ocorrem das zonas rurais para os centros urbanos e inter-fronteiras (dentro do país ou para o exterior).

A migração é resultado da disparidade entre regiões/países mais desenvolvidos e menos desenvolvidos, e de crises econômicas que refletem a redução do nível de emprego formal, da precarização e a exploração do trabalho de mulheres, crianças e adolescentes, dentre outros fatores, do avanço extraordinário das comunicações, que permite divulgar oportunidades de trabalho que atraem estes segmentos para a emigração e imigração.

$\mathrm{Na}$ relação entre tráfico interno, tráfico internacional e migração, destaca-se a organização do mercado transnacional, do crime organizado, a partir da revelação de outros mecanismos de inserção da mulher, crianças e adolescentes no tráfico para fins sexuais, por exemplo: o trabalho doméstico, o recrutamento para casamento e a busca de emprego dentro e fora do país (agências de casamento e trabalho). Isto é, combina a situação de exclusão social, desemprego e trabalho precário, viabilizando a inserção das mulheres, crianças e adolescentes em situação de vulnerabilidade social no mercado da indústria sexual e/ou outras formas de violência inter-relacionadas em nível local e global.

Por outro lado, as fronteiras são espaços socioculturais importantes no estudo da inter-relação entre migração e tráfico para fins sexuais. Leonardi (2000, p. 54), na sua pesquisa sobre as fronteiras amazônicas, ao descrever a complexidade das redes sociais e o caráter dinâmico e interativo dos garimpeiros, madeireiros, caminhoneiros, prostitutas, gateiros, soldados, imigrantes, turistas, pequenos comerciantes e a mobilidade dos mesmos na região, indica a complexidade que envolve qualquer esforço em "padronizar comportamentos sexuais" e outras situações de caráter sociocultural e criminosa, uma vez que a lógica que rege essas redes sociais móveis está diretamente relacionada ao cotidiano das relações que são construídas nestas localidades.

O importante desta discussão é identificar que tráfico, mobilidade/ migração, fronteiras e exploração sexual comercial são questões distintas, mas que na prática elas se inter-relacionam e possibilitam a configuração do tráfico de mulheres, crianças e adolescentes para fins sexuais.

Os indicadores macro/geo/sociais, tais como os projetos de desenvolvimento econômico, mobilidade, migração e fronteiras, 
determinam as razões sociais do fenômeno, e os indicadores culturais como: gênero, geração, raça e etnia descortinam os valores culturais que fortalecem as relações de poder e dominação entre mulheres e homens, ricos e pobres, adultos e crianças. E os indicadores de exploração sexual comercial (turismo sexual, prostituição e pornografia) configuram a indústria sexual, onde o tráfico se manifesta. A inter-relação entre esses indicadores, possibilita estabelecer as razões que explicam o fenômeno.

A crise ética e política da sociedade global fragiliza a construção democrática de resolução ou de enfrentamento do tráfico de mulheres, crianças e adolescentes para fins de exploração sexual comercial, uma vez que os governos não estão apresentando propostas fundamentadas nestes indicadores. Existe uma análise frágil e reducionista do problema, o que permite a construção ou o fortalecimento de uma ideologia moralista, vitimizadora, repressiva e assistencialista, o que vai motivar ações de enfrentamento voltadas muito mais para a repressão e o controle da mobilidade das pessoas entre os países.

Desta forma, reconhecemos a importância da re-leitura da legislação nacional e internacional para o enfrentamento do fenômeno. No entanto, essas medidas devem vir acompanhadas de mudanças objetivas nas relações de exploração e de dominação, entre os blocos hegemônicos (G-8) e as regiões da América Latina e Caribe, África e alguns países da Ásia e Leste Europeu (regiões exportadoras de pessoas, em especial de mulheres, crianças e adolescentes para o tráfico com fins sexuais) que apresentam um quadro social dramático, um processo de refluxo democrático e conflitos étnicos, religiosos e militares, agravado por essas relações.

O fenômeno torna-se ainda mais complexo porque, embora o mesmo esteja "politicamente agendado" pelas organizações mundiais de defesa dos direitos humanos como violação de direitos, inclusive sobre a sexualidade, esta questão não é vista da mesma forma pelo conjunto da sociedade e suas instituições.

Este tema é imbuído de visões conservadoras, principalmente por se tratar de uma violação relacionada à sexualidade e formas distintas de prostituição, assunto de âmbito privado, que culturalmente esteve sobre uma racionalidade moral repressiva, objeto de tabu e de discriminação pela sociedade e suas instituições. Tratar publicamente esta temática requer confrontar os diferentes projetos de sexualidade e a sua relação com a violência sexual frente aos projetos societários.

No caso do nosso estudo, estamos revelando um projeto de sexualidade racionalizado pelo mercado violento da indústria sexual, cuja relação é fortalecida por uma oferta de mulheres e meninas (havendo inclusão do sexo masculino), em situação de vulnerabilidade social, a uma demanda (especialmente masculina, pertencente a diferentes 
classes sociais), potencialmente voltada para o consumo de serviços sexuais pagos e sem dar importância a natureza violadora do seu ato, especialmente se for sob condições de exploração e escravidão.

O que está em jogo é a satisfação do desejo sexual (o ato sexual, de propriedade do consumidor), o lucro (acumulado pelo mercado, proprietário da mercadoria) e as relações de poder, exploração e dominação sobre mulheres, crianças e adolescentes, em situação de vulnerabilidade social, no contexto da prostituição, do turismo sexual, da pornografia e de outras formas de exploração e trabalho forçado e escravo.

A banalização desta violência não é visível apenas nas relações de mercado, ela se entranha nas relações familiares, no Estado e na sociedade como se fosse uma relação natural, corroborando a omissão e o silêncio, que culturalmente se esconde sob o manto moralista, repressivo e patriarcal, dificultando a desmobilização da ação do usuário e das redes de comercialização do sexo.

O desafio da sociedade civil, através das ONGs, movimentos, fóruns e pactos, dentre outros, é ampliar a correlação de forças, junto às forças sociais locais e internacionais, para interferir nos planos e estratégias dos blocos hegemônicos (Alca, Otan, Nafta, Mercosul e outros) a fim de diminuir as disparidades sociais entre os países, dar visibilidade ao fenômeno para desmobilizar as redes do crime organizado (Yakusa, máfia russa, tríade chinesa e outros), e criar instrumentos legais e formas democráticas de regular a ação do mercado global, a omissão do Estado e a ação do explorador, entendendo que o tráfico de mulheres, crianças e adolescentes é, sobretudo, uma questão social.

Essas organizações são fundamentais na construção e consolidação de espaços de denúncias e de publicização do fenômeno, enquanto setores estratégicos de mobilização e articulação em defesa dos direitos humanos.

\section{Bibliografia}

AGÊNCIA DE NOTÍCIAS DOS DIREITOS DA INFÂNCIA. O grito dos inocentes: uma análise do tratamento jornalístico dos crimes sexuais. Brasília, 2002. (Revista n. 12).

ASSOCIAÇÃO INTERNACIONAL DE DIREITO PENAL (AIDP). Relatório sobre o tráfico internacional de mulheres e crianças: aspectos regionais e nacionais. Rio de Janeiro: AIDP, 2002.

BASSIOUNI, Cherif M. Tráfico de mulheres e crianças para fins de exploração sexual. In: COLÓQUIO INTERNACIONAL DO RIO DE JANEIRO. Anais. Rio de Janeiro, 2002. 
BOBBIO, Norberto. O conceito de sociedade civil. Rio de Janeiro: Graal, 1982.

BRASIL. MINISTÉRIO DAS RELAÇÕES EXTERIORES (MRE). Tráfico de mulheres, crianças e adolescentes para fins de exploração sexual. Brasília, 2001. (mimeogr.).

CECRIA. Relatório preliminar da pesquisa sobre tráfico de mulheres, crianças e adolescentes para fins de exploração sexual comercial. Brasília: CECRIA, 2002.

COMISSÃO EUROPÉIA, JUSTIÇA E DOS ASSUNTOS INTERNOS. Tráfico de Mulheres. A miséria por trás da fantasia: da pobreza à escravatura sexual. 2001. Disponível em: <http://europa.eu.int/comm/employment_social/ equ_opp/index_em.htm>.

DAVIDSON, O'Connel J. El explotador sexual: niños. In: CONGRESO MUNDIAL CONTRA LA EXPLOTACIÓN SEXUAL COMERCIAL DE LOS NIÑOS, 2., Yokohama, Japón, 2001.

DEPAUL COLLEGE, IILDH/OEA. Resumen ejecutivo sobre estudio del tráfico de mujeres y niños para la explotación sexual en las Américas. Chicago, ILL, 2000. (Mimeogr.).

DOSSIÊ tráfico de mulheres brasileiras para o exterior. Brasília: Comissão de Direitos Humanos da Câmara Federal, julho de 1996.

JORDAN, Anne. Tráfico de seres humanos: escravidão ao nosso redor. In: QUESTÕES globais: relatório do Conselho da Europa sobre escravidão doméstica, submetido à Comissão de Oportunidades Iguais para Homens e Mulheres pelo relator John Connor. Disponível em <http://stars.coe.fr/ doc/doc01/EDOC9102.htm>.

LEAL, Gustavo. Investigación regional sobre tráfico, prostitución, pornografia infantil y turismo sexual infantil en México y Centroamérica. Costa Rica: Casa Alianza, ECPAT, 2001.

LEAL, Maria de Fátima; HAZEU, Marcel. Relatório do I Seminário Internacional sobre Tráfico de Seres Humanos. Brasília: PESTRAFI/CECRIA, 2000. (Mimeogr.)

LEAL, Maria Lúcia P. Exploração sexual comercial na América Latina e Caribe,1998.

A mobilização das ONGs no enfrentamento à exploração sexual comercial de crianças e adolescentes no Brasil. São Paulo, 2001. $271 \mathrm{f}$. Tese (Doutorado em Serviço Social) - Pontifícia Universidade Católica de São Paulo.

LEI de Proteção às Vítimas do Tráfico e Violência: trecho da legislação aprovada pelos Estados Unidos. In: QUESTÕES globais. Disponível em: <http:// stars.coe.fr/doc/doc01/EDOC9102.htm>. 
LEITE, Maria Jaqueline de Souza. Reflexões sobre migração e o tráfico de mulheres. Salvador: CHAME, 2000.

LEONARDI, Victor P. de Barros. Fronteiras amazônicas: saúde e história social. Brasília: Paralelo 15; São Paulo: Marco Zero, 2000.

MARTINEZ, A. Ramirez. Tráfico de mujeres, niños, niñas y adolescentes para la explotación sexual comercial en la Republica Dominicana. Republica Dominicana, 2001. (Mimeogr.).

MENESCAL, Andréa Koury. História e gênese das ONGs. São Paulo: Estação Liberdade, 1996.

NOGUEIRA NETO, W. Tráfico de mulheres, crianças e adolescentes para fins de exploração sexual no Brasil: dimensão jurídico-social. Brasília, 2001. (mimeogr.).

POLÍCIA FEDERAL. Relatório sobre o tráfico de mulheres, crianças e adolescentes para fins de exploração sexual. Brasília: MJ/DPF/DPCI/INTERPOL, 2001.

PROGRAMA Mujer, Justicia y Género: textos básicos sobre tráfico internacional de mujeres y niñas en America Latina para la industria sexual. Genebra: ILANUD/ONU, 2001.

PROTOCOLO to Prevent, Suppress and Punish Trafficking in Persons, Especially Women and Children, Supplementing the United Nations Convention Against Transnational Organized Crime. Genebra: United Nations, 2000.

SEYFERTH, Geralda. Imigração e nacionalismo: o discurso da exclusão e a política imigratória no Brasil. In: SEMINÁRIO INTERNACIONAL SOBRE MIGRAÇÕES INTERNACIONAIS. Contribuições para as políticas. BrasíliaDF: CNPD, 2000.

TRÁFICO de Mulheres, Crianças e Adolescentes para fins de Exploração Sexual no Brasil. Brasília: PESTRAFI/CECRIA/IIDH/OEA, 2000. (Mimeorg)

UNICEF. La trata de niños com fines de explotación sexual. In: CONGRESO MUNDIAL CONTRA LA EXPLOTACIÓN SEXUAL COMERCIAL DE LOS NIÑOS, 2., Yokohama, Japon, 2001.

VERMEULEN, Gert. Repporteur of international trafficking in women and children. Siracusa: Internacional Association of Penal Law, 2001.

VELASQUEZ, T. Cordero. El tráfico de mujeres y niñas y la participación de las mujeres en este delito: una aproximación contextual. Quito, Ecuador, 2001. (Mimeogr.). 